\title{
Spatial Variations and Determinants of Acute Malnutrition among Under-Five Children in Ethiopia: Evidence from 2019 Ethiopian Demographic Health Survey
}

Binyam Tariku Seboka ( $\sim$ bini555tar@gmail.com )

Dilla University https://orcid.org/0000-0002-8309-5986

Tilahun Dessie Alene

Wollo University

Habtamu Setegn Ngusie

Mettu University

Samuel Hailegebreal

Arba Minch University

Delelegn Emwodew Yehualashet

Dilla University

Girma Gilano

Arba Minch University

Mohammedjud Hassen Ahmed

Mettu University

Robel Hussen Kabthymer

Dilla University

Girum Gebremeskel Kanno

Dilla University

Getanew Aschalew Tesfa

Dilla University

\section{Research}

Keywords: Acute malnutrition, under-five children, wasting, spatial analysis, multilevel analysis, Ethiopia.

Posted Date: July 9th, 2021

DOI: https://doi.org/10.21203/rs.3.rs-680595/v1

License: (c) (i) This work is licensed under a Creative Commons Attribution 4.0 International License. 
Version of Record: A version of this preprint was published at Annals of Global Health on January 1st, 2021. See the published version at https://doi.org/10.5334/aogh.3500. 


\section{Abstract}

Background: Childhood acute malnutrition, in the form of wasting defined by a severe weight loss as a result of acute food shortage and/or illness. It is a critical public health problem that needs urgent attention in developing countries, like Ethiopia. Despite its variation between localities, the risk factors and its geospatial variation were not addressed enough across the various corner of the country. Therefore, the current study was undertaken to assess spatial variation and factors associated with acute malnutrition among under-five children in Ethiopia.

Methods: A total weighted sample of 4,955 under-five children were included from the 2019 Demographic and Health Survey. Getis-Ord spatial statistical tool used to identify the hot and cold spot areas of severe and acute malnutrition. A multilevel multivariable logistic regression model using was used to examine predictors of acute malnutrition. In the multivariable multilevel analysis, Adjusted Odds Ratio with $95 \% \mathrm{Cl}$ was used to declare significant determinants of acute malnutrition among children.

Result: Among 4,955 under-five children, $7 \%$ of them were wasted and $1 \%$ of them were severely wasted in Ethiopia during the 2019 national demographic survey. The distribution was followed some spatial geo-locations where most parts of Somali were severely affected ( $R R=1.46, P 37$ value $<0.001)$, and the distribution affected few areas of Afar, Gambella, and Benishangul Gumz regions. Factors that significantly associated with childhood wasting were: gender(male)1.9(1.3-2.7), age (above 36 months) 0.5 (0.2-0.9), wealth index(richest) $0.5(0.2-0.8)$, and water source(unimproved source) $1.5(1.0-2.3)$.

Conclusion and Recommendation: Our finding implies, the distribution of childhood wasting was not random. Regions like Afar, Somali, and pocket areas in Gambella and SNNP should be considered as priority areas nutritional interventions for reducing acute malnutrition. The established sociodemographic and economic characteristics can be also used to develop strategies.

\section{Introduction}

Childhood malnutrition is well estimated as the major underlying risk factor for morbidity and mortality in children under 5 years $[1,2]$. Acute malnutrition also known as wasting is characterized by a rapid deterioration in nutritional status over a short period that causes a child to become too thin for his or her height because of weight loss or failure to gain weight [3-5]. For children, it can be measured using the weight-for-height nutritional index or mid-upper arm circumference [6, 7]. It is defined as moderate acute malnutrition (MAM) and severe acute malnutrition (SAM) whereas; MAM: is WHZ $\geq-3 Z$ score \& $<-2 Z$ score or MUAC $\geq 115 \mathrm{~mm} \&<125 \mathrm{~mm}(\geq 11.5 \mathrm{~cm} \mathrm{\&}<12.5 \mathrm{~cm})$ and SAM: is defined by visible severe wasting, or by the presence of bilateral pitting edema of nutritional origin, or $\mathrm{WHZ}<-3 \mathrm{Z}$ score or MUAC $<115 \mathrm{~mm}$ $(<11.5 \mathrm{~cm})$ in children aged 6-59 months [2].

Globally, between 8 to 11 million under-five children die each year [8]. More than $35 \%$ of these deaths are attributed to undernutrition and 1 in 12 children ( $8 \%, 52$ million) were wasted [9]. It is also one of the major causes of childhood deaths in developing countries [10-12]. More than $90 \%$ of undernourished 
people live in developing countries [2]. Africa carries the heaviest burden of under-nutrition [9], in which a recent study indicated that $39.9 \%$ of under-five children group affected by malnutrition [13], and the prevalence of wasting in East Africa is 6\% [14].

Ethiopia has adopted a multi-sectorial nutrition policy and has been implementing nutrition programs with some success $[15,16]$. In this regard, Ethiopia design the program called "the sustainable undernutrition reduction in Ethiopia (SURE)" which is a government-led multi-sector intervention that helps to integrate the work of the health and agriculture sectors to deliver a complex multicomponent intervention to improve child feeding, diversified diet, and nutritional behavioral modification to reduce undernutrition[16]. However, under-nutrition remains high and suffers from a very high burden of acute and chronic malnutrition [17], with almost half of Ethiopian children chronically malnourished and 1 in 10 children wasted [18]. According to the Ethiopian Demographic and Health Survey (EDHS) quick list of, $2005,2011,2016$, and 2019 the prevalence of under-five wasting was $12.2 \%, 9.7 \%, 9.9 \%$, and $7.0 \%$ respectively [18-21].

Multiple factors contribute to childhood wasting. The common determinants reported by several studies include gender, age of the child [7, 22-24], monthly income [22, 24], diarrhea in the previous two weeks [25-27], not consuming additional food during pregnancy/lactation [28, 29], non-exclusive breastfeeding practices [26, 30], larger family size [26], mothers education [22, 26], presence of ARI [26, 31], attending ANC $[7,29,32]$, immunization status [33, 34], mother not having consumed extra food during this pregnancy/lactation $[4,22]$.

Most of the previous studies conducted in Ethiopia were not examine the extent of the variation within and between regional wasting in Ethiopia and the variation of predictors across regions. Moreover, the previous studies conducted in Ethiopia used binary logistic regression which leads to biased results. The assumptions of independence among individuals within the same clusters and of equal variance across clusters are violated in the case of grouped data [35]. Hence, a multi-level analysis, which has a number of advantages over binary logistic regression, is the appropriate statistical analysis method for such a study. The main concerns of the authors in this study were to identify the spatial distribution and associated factors of wasting aged 6 to 59 months in Ethiopia using spatial multilevel analysis.

\section{Methods And Materials}

\section{Study design and Setting}

We have used the Ethiopian Demographic Health Information Survey (EDHS) of 2019 to identify factors associated with wasting which were community-based cross-sectional surveys conducted across the country. Ethiopia, the most populous country in Africa, is situated in the Horn of Africa between 3 and 15 degrees north latitude and 33 and 48 degrees east longitude $\left(3^{\circ}-15^{\circ} \mathrm{N}\right.$ and $\left.33^{\circ}-48^{\circ} \mathrm{E}\right)$. It has an administrative structure of nine regional states (Tigray, Afar, Amhara, Oromiya, Somali, BenishangulGumuz, Southern Nations Nationalities and People (SNNP), Gambela, and Harari) and two city 
administrations (Addis Ababa and Dire Dawa). These are subdivided into 68 zones, 817 administrative districts which are further divided into 16,253 Kebeles, the smallest administrative units of the country. It has an estimated population of 114.96 million in 2020, which makes it second in Africa and 12th in the world's most populous country.

\section{Data source, Extraction, Sampling Procedure, and Study Participants}

Our data source was the EDHS survey which was collected in 2019. EDHS is collected every five years by the Ethiopian Central Statistical Agency (CSA) along with ICF International and funded by USAID. The data sets for EDHSs were downloaded in SPSS format with permission from the Measure DHS website (http://www.dhsprogram.com). The shapefile of the map of Ethiopia has been accessed as an opensource without restriction from Open Africa website (https://africaopendata.org/dataset/ethiopiashapefiles).

The EDHSs samples were collected using stratified in a two-stage cluster sampling technique. In the first stage, each region was stratified into urban and rural areas. In the second stage of selection, a fixed number of households per cluster were selected with an equal probability of systematic selection from the newly created household listing. All women age 15-49, who were either permanent residents of the selected households or visitors who slept in the household the night before the survey, were eligible to be interviewed. All under-five children within 5 years during the surveys in Ethiopia were the source of the population for this study, whereas all under-five children in the selected enumeration areas (EAs) within 5 years during the survey were the study population. Ultimately, a total representative sample of 5,057 under-five children was included in the 2019 survey

$[18,20,21]$.

Geographic coordinates of each survey cluster were also collected using Global Positioning System (GPS) receivers. To ensure confidentiality, GPS latitude/longitude positions for all surveys were randomly displaced before public release. The detailed procedure has been presented in each EDHSs report

$[18,20,21]$.

\section{Variables of study}

\section{Outcome variable}

In this study, the dependent variable was under-five wasting which is defined as the percentage of underfive children whose weight-for-height z-score (WHZ) is below - 2 SD in the national center for health statistics (NCHS) growth curve. Therefore, we consider under-five wasting (wasted $=1$ or not wasted $=0$ ) as the outcome variable [14]. 


$$
Y i j=\left\{\begin{array}{c}
1, \quad \text { if there is wasting } \\
0 \text { if there is no wasting }
\end{array}\right.
$$

When $Y$ is the outcome variable (wasting), while $i$ is for the individual-level factors, while $j$ is for the community factors.

\section{Independent variables}

The independent variables included: socio-demographic and economic factors: age, sex, occupation, educational status, head of household, wealth index, and religion), geographical factors (region, residence, and temperature), maternal health service utilization factors (antenatal care, place of delivery, and postnatal care), nutritional status of mother (BMI and HFA), birth weight, the timing of breastfeeding, clinical factors (anemic status of the mother, anemic status of the child), drinking safe water, latrine use and media exposure of respondents. Early initiation of breastfeeding -infants who are sucking the breast milk within one hour of birth. Introduction of solid, semi-solid, or soft foods (6-8 months), birth interval were factors for childhood wasting

$[3,4,7,24-26,30,32,36]$.

\section{Data management and analysis}

After downloading EDHS data, sample weights were applied to compensate for the unequal probability of selection between each stratum, data cleaning and recording were carried out in SPSS statistical software version 24. The EDHS datasets were joined to Global Positioning System (GPS) coordinates of EDHS using the joining variable as recommended by DHS measure.

\section{Spatial analysis}

The data was exported into Arc GIS 10.8 to visualize key estimation, clusters, and regional variation among wasting. For the spatial analysis, ArcGIS version 10.8 and Sat Scan version 9.6 statistical software were used for exploring the spatial distribution, global spatial autocorrelation, spatial interpolation, and for identifying significance. The spatial autocorrelation (Global Moran's I) statistic measure was used to evaluate whether the spatial distribution of wasting was random or not. Moran's I is a spatial statistic used to measure spatial autocorrelation by taking the entire data set and produce a single value that ranges from -1 to +1 . Moran's I values close to $-1,1$, and 0 indicate wasting was dispersed, wasting was clustered, and wasting was distributed randomly, respectively. A statistically significant Moran's I $(P<0: 05)$ leads to rejection of the null hypothesis (wasting is randomly distributed) and indicates the presence of spatial autocorrelation.

The local Getis-Ord G index ( $\mathrm{LGi}$ ) was used to analyze causality autocorrelation into positive and negative. If the prevalence rates had similar attributes of high or low values (high-high or low-low autocorrelation), they were defined as positive autocorrelation whereas if the attributes had opposing 
values (high-low or low-high autocorrelation) they were defined as negative autocorrelation. Moreover, the spatial interpolation technique was applied to predict the un-sampled /unmeasured value from sampled measurements.

Autocorrelation can be classified into positive and negative correlations through the local Getis-Ord G positive autocorrelation occurs when similar values are clustered together on a map (high rates surrounded by nearby high rates or low rates surrounded by nearby low rates). Negative autocorrelation indicates different values clustered together on a map, that is, high values surrounded by nearby low values or low values surrounded by nearby high values. Statistical significance of autocorrelation was determined by z-scores and $p$-value with a $95 \%$ level of confidence. The distribution and variations of wasting prevalence rates among children across the country were displayed on the map.

Using Kuldorff's SaTScan version 9.6 program, spatial scan statistical analysis was used to classify statistically important hotspot areas. To fit the Bernoulli model, we used wasting under-five children as cases and not wasted children as controls. The numbers of cases in each location have Bernoulli distribution and a maximum spatial cluster size of $<50 \%$ of the population was used as an upper limit. Zscore is computed to determine the statistical significance of clustering, and the $P$-value was used to determine if the number of observed 6 to 59 months aged children who were within the potential cluster was significant or not. The null hypothesis of no clusters was rejected when the $P$-value $\leq 0.05$. Based on 999 Monte Carlo replications the significant clusters were identified and ranked based on their likelihood ratio test

$[37,38]$.

\section{Statistical analysis}

The multivariable multilevel logistic regression model was used to determine the effect of different factors on wasting. For this multilevel analysis, four models were constructed. Those are the null model without predictors (Model I), model II with only individual-level variables, model III with only communitylevel variables, and model IV both individual-level and community-level variables. For model comparison, we used the log-likelihood ratio (LLR) and deviance. The highest log-likelihood or the smallest deviance wins the best-fitted model. Therefore, model III which includes both individual and community-level variables was selected as the best fit model for the data.

An adjusted OR (AOR) with 95\% Cls was computed to identify the independent factors of under-five wasting at $p$ value $<0.05$. A multicollinearity test was done in order to rule out a significant correlation between variables. If the values of variance inflation factor (VIF) were lower than 10 , then the collinearity problem was considered less likely. Correlation coefficient (ICC), a proportional change in community variance (PCV), and median odds ratio (MOR) were used for measuring variation or random effect [35]. 
The intra-class correlation coefficient is a measure of within-cluster variation (i.e. the variation between individuals within the same cluster). The PCV is a measurement of the total variation attributed to individual and/or community-level factors at each model. The MOR is the median odds ratio between the individual of higher propensity and the individual of lower propensity when comparing two individuals from two different randomly chosen clusters and it measures the unexplained cluster heterogeneity (the variation between clusters) by comparing two persons from two randomly chosen different clusters. The MOR measure is always greater than or equal to " 1 ". If The MOR measure is " $1 "$ ", there is no variation between clusters. The within-cluster correlation was measured using intra-cluster correlation (ICC) which is expected to be $10 \%$ to use the model. The ICC, PCV, and MOR were determined using the estimated variance of clusters using the following formula:

$I C C=\frac{V}{V+\pi 2 / 3}$, Where $\mathrm{V}$ is a variance of estimated clusters, MOR $=E x p \sqrt{2 \times \mathrm{V} \times 0.6745}$

$P C V=\frac{(\mathrm{VA}-\mathrm{VB})}{V \mathrm{~B}} \times 100$, were VA=variance of the initial model; $\mathrm{VB}=$ variance of the model with more terms.

The multilevel analysis model is one of the analysis methods that can correctly handle the correlated data. A multilevel model evaluates how factors at different levels affect the dependent variable. A multilevel model provides correct parameter estimates by correcting the biases introduced from clustering by producing correct $\mathrm{SEs}$, thus producing correct $\mathrm{Cl}$ and significance tests.

\section{Ethical consideration}

Publicly available EDHSs data were used for this study. Ethical approval of EDHS was obtained from the ICF Institutional Review Board (IRB), Ethiopia Health and Nutrition Research Institute Review Board, and the Ministry of Science and Technology. For this particular study, a brief description of the protocol was submitted to the MEASURE DHS program to access and analyze the data. Permission was obtained from the program to access and analyze the data. During EDHS data collection, Informed consent was taken from each participant, and all identifiers were removed and the confidentiality of the information was maintained.

\section{Result}

\section{Socio-demographic characteristics}

Table 1 reports selected socio-demographic and economic characteristics of the included participants. A total weighted sample of 4,955 children aged 6-59 months with their mothers was included in this study. Of the total children, $2,008(40.5 \%)$ were in the age range of 36-59 months. The majority of the children, 2,517 (50.1) were males. Regarding region, 2,017(39.9\%), 1,016(20.1\%), and 964(19.1\%) were from Oromia, Southern Nation Nationalities and Peoples Region (SNNPR), and Amhara respectively. Of the total, $3,787(75.0 \%)$ lived in the rural areas and $1,170(23.6 \%)$ were from the poorest households (Table 1 ). 
Table 1

The descriptive characteristics of the study participants

\begin{tabular}{|c|c|c|c|c|c|}
\hline \multirow[t]{2}{*}{ Variables } & \multirow{2}{*}{$\begin{array}{l}\text { Wasted } \\
\text { Weighted } \\
\text { frequency (\%) }\end{array}$} & \multicolumn{2}{|l|}{ Not wasted } & \multirow{2}{*}{$\begin{array}{l}\text { Wasted } \\
\text { Weighted } \\
\text { frequency (\%) }\end{array}$} & \multirow{2}{*}{$\begin{array}{l}\text { Not wasted } \\
\text { Weighted } \\
\text { frequency (\%) }\end{array}$} \\
\hline & & $\begin{array}{l}\text { Weighted } \\
\text { frequency (\%) }\end{array}$ & Variables & & \\
\hline \multicolumn{3}{|l|}{ Sex of child } & \multicolumn{3}{|l|}{ Wealth index } \\
\hline Male & $223.8(62.7)$ & 2293.6(49.9) & Poorest & $135.5(37.9)$ & $1034(22.5)$ \\
\hline Female & $132.9(37.3)$ & $2305.0(50.1)$ & Poorer & $80.0(22.4)$ & $1002.4(21.8)$ \\
\hline \multicolumn{3}{|l|}{ Age of child } & Middle & $47.1(13.2)$ & $875.7(19.0)$ \\
\hline $0-5 m$ & $48.6(13.6)$ & $467.9(10.2)$ & Richer & $55.4(15.5)$ & $809.8(17.6)$ \\
\hline $6-11 m$ & 29.3(8.2) & $437.3(9.5)$ & Richest & $38.7(10.9)$ & $876.4(19.1)$ \\
\hline $12-23 m$ & $78.8(22.1)$ & $911.3(19.8)$ & \multicolumn{3}{|c|}{ Child birth order } \\
\hline $24-35 m$ & $76.3(21.4)$ & $897.8(19.5)$ & First & 113.6(31.8) & 1816.6(39.5) \\
\hline$>36 \mathrm{~m}$ & 123.6(34.6) & $1884.4(41)$ & Second & $80.2(22.5)$ & $1216.2(26.5)$ \\
\hline \multicolumn{3}{|l|}{ ANC visit } & Third & $162.9(45.7)$ & 1565.9(34.1) \\
\hline Yes & $161.2(65.1)$ & $2524.7(75.8)$ & \multicolumn{3}{|c|}{ Mother educational level } \\
\hline No & $86.3(34.9)$ & $803.8(24.2)$ & $\begin{array}{l}\text { No } \\
\text { education }\end{array}$ & $247.7(69.5)$ & $2426(52.8)$ \\
\hline \multicolumn{3}{|c|}{ Under-five children in house } & Primary & $86.0(24.1)$ & $1655(36.0)$ \\
\hline 1 child & $103.8(29.2)$ & $1836.4(40.1)$ & $\begin{array}{l}\text { Secondary\& } \\
\text { above }\end{array}$ & $122.9(6.4)$ & $516.5(11.2)$ \\
\hline 2 child & $180.0(50.6)$ & $2124.7(46.4)$ & \multicolumn{3}{|c|}{ Household size } \\
\hline 3 child & $72.2(20.3)$ & $621.7(13.6)$ & $1-4$ & $70.7(19.8)$ & 1333.4(29.0) \\
\hline \multicolumn{3}{|c|}{ Source of drinking water } & $5-9$ & $248.6(69.7)$ & $2951.5(64.2)$ \\
\hline unimproved & $129.9(36.4)$ & 1626.1(35.4) & $\begin{array}{l}10 \text { and } \\
\text { more }\end{array}$ & $37.4(10.5)$ & $313.7(6.8)$ \\
\hline Improved & $226.8(63.6)$ & $2969.4(64.6)$ & Residence & & \\
\hline \multicolumn{3}{|c|}{ Vaccination status } & urban & 70.4(19.7) & $1161.9(25.3)$ \\
\hline Yes & $63.4(17.5)$ & $825.7(17.9)$ & Rural & $286.3(80.3)$ & $3436.7(74.7)$ \\
\hline No & $294.4(82.5)$ & 3772.8(82.0) & & & \\
\hline
\end{tabular}




\section{Spatial distribution and clustering of wasted children In Ethiopia}

Figure 1 shows the distribution of acute and severe malnutrition regionally among under-five children's in Ethiopia. The prevalence of childhood wasting shows a variation across regions; in 2019, the range was from $26.4 \%$ in the Oromia region to $0.2 \%$ in the Harari region. However, the highest distribution of both acute and severe malnutrition was found in the SNNP and Somali region.

The spatial distribution of wasted and severely wasted children varied across regions in Ethiopia. Results of the Global Moran's I values ( 0.21 and 0.11 ) indicated that there was significant clustering of wasted and severely wasted children, respectively. Besides, the Z-scores of 4.58 and 2.52, respectively, also indicated a clustered pattern of wasted and severely children (Fig. 2-3)

As we see in Figs. 4 and 5,The highest number of wasted and severely wasted children was observed in the Somali, Afar, and South Omo of the SNNP region. Further, Fig. 6 shows the hotspot areas of wasting among under-five children in Ethiopia. In the 2019 EDHS, the highest prevalence of wasted children (hotspots) was identified in Somali, Afar, SNNP, and Gambella regions. We observed that the prevalence of wasting is worse in the Somali region of Ethiopia. In regard to severely wasted children, the local (Getis-Ord Gi*) statistics indicated that Somali and South Omo of SNNP were identified as hotspot areas; whereas Addis Ababa and the central part of Oromia were identified as cold spots region of the country (Fig. 7).

\section{Kriging interpolation of wasting among children}

The kriging interpolation analysis mapped the estimated distributions of wasting interpolating the available data to the areas where data were not collected. The red prediction areas show predicted prevalent areas of wasting among children. Based on EDHS 2019, Kriging interpolation predict that wasted children were detected in the Somali, Afar, border areas of Tigray, South Omo of SNNPR, and border areas of Gambella regions(Fig. 8). Furthermore, Somali and SNNP(South Omo) areas were predicted as more risky areas for Severe malnutrition among children compared to other regions (Fig. 9).

\section{Spatial scan statistical analysis}

In 2019 EDHS, a total of 25 significant clusters with wasted and 13 clusters with severely wasted children were identified. Of which, 21 and 12 of them were most likely (primary) clusters, respectively. Both spatial windows were located in the Somali region of Ethiopia. The spatial window for wasted children was centered at $639662 \mathrm{~N}, 44.465853 \mathrm{E}$ with $381.04 \mathrm{~km}$ radius, with a relative risk (RR) of 2.9 and LogLikelihood ratio (LLR) of 46.96 , at $p<0.000$. This means children within the spatial window had 2.9 times more wasted than children outside the window (Table 2, Fig. 10). 
Table 2

Significant spatial clusters of wasting among under-five children in Ethiopia, 2019

\begin{tabular}{|c|c|c|c|c|c|c|c|c|}
\hline Year & Cluster & $\begin{array}{l}\text { Enumeration } \\
\text { areas(clusters } \\
\text { detected) }\end{array}$ & $\begin{array}{l}\text { Coordinates } \\
\text { /radius }\end{array}$ & Population & Cases & RR & LLR & $\begin{array}{l}\mathrm{P} \text { - } \\
\text { value }\end{array}$ \\
\hline 2019 & 1 & $\begin{array}{l}135,123,140, \\
137,138,124, \\
131,145,132, \\
122,134,136, \\
142,133,139 \\
129,121,130 \\
107,250,141\end{array}$ & $\begin{array}{l}6.639662 \mathrm{~N}, \\
44.465853 \\
\mathrm{E} / 381.04 \\
\mathrm{~km}\end{array}$ & 515 & 116 & 2.90 & 46.96 & $\begin{array}{l}<.000 \\
0.00\end{array}$ \\
\hline & 2 & 193 & $\begin{array}{l}4.495034 \mathrm{~N} \\
36.230625 \\
\mathrm{E} / 0 \mathrm{~km}\end{array}$ & 36 & 20 & 6.25 & 24.95 & $\begin{array}{l}<.000 \\
0.00\end{array}$ \\
\hline & 3 & $42,40,69$ & $\begin{array}{l}9.548779 \mathrm{~N}, \\
40.084216 \\
\mathrm{E} / 39.15 \\
\mathrm{~km}\end{array}$ & 60 & 20 & 3.75 & 13.72 & $\begin{array}{l}<.000 \\
0 .\end{array}$ \\
\hline
\end{tabular}

Furthermore, the severely wasted clusters' spatial window was centered at $5.856584 \mathrm{~N}, 43.726016 \mathrm{E}$ with $284.96 \mathrm{~km}$ radius, with a RR of 6.4 and LLR of 24.2, at $p<0.001$ (Table 3, Fig. 11).

Table 3

Significant spatial clusters severely wasted children in Ethiopia, 2019

\begin{tabular}{|c|c|c|c|c|c|c|c|c|}
\hline Year & Cluster & $\begin{array}{l}\text { Enumeration } \\
\text { areas(clusters } \\
\text { detected) }\end{array}$ & $\begin{array}{l}\text { Coordinates } \\
\text { /radius }\end{array}$ & Population & Cases & RR & LLR & $\begin{array}{l}\mathrm{P} \text { - } \\
\text { value }\end{array}$ \\
\hline 2019 & 1 & $\begin{array}{l}137,138,123 \\
135,142,136 \\
145,134,140 \\
131,141,122\end{array}$ & $\begin{array}{l}5.856584 \mathrm{~N} \\
43.726016 \mathrm{E} \\
/ 284.96 \mathrm{~km}\end{array}$ & 291 & 26 & 6.4 & 24.2 & $\begin{array}{l}<.001 \\
0.001\end{array}$ \\
\hline & 2 & 193 & $\begin{array}{l}4.495034 \mathrm{~N}, \\
36.230625 \mathrm{E} \\
/ 0 \mathrm{~km}\end{array}$ & 36 & 6 & 9.8 & 8.56 & $\begin{array}{l}<.030 \\
0.030\end{array}$ \\
\hline
\end{tabular}

\section{Multilevel Analysis}


From the total variation in acute malnutrition across the participants, 61\% in 2019 EDHS was attributable to clustering. The clustering effect shown up here directed us to take multilevel analyses (Table 4).

Table 4

Model estimates for factors associated with acute malnutrition in 2019

\begin{tabular}{|lllll|}
\hline 2019 EDHS & Model 0 & Model 1 & Model 2 & Model 3 \\
\hline Inter-cluster correlation(ICC) & 0.61 & 0.22 & 0.11 & 0.04 \\
\hline Log-likelihood ratio(LLR) & -1580.1 & -1014.7 & -1480.7 & -984.0 \\
\hline Proportional change in variance(PCV) & Reference & 0.61 & 0.71 & 0.72 \\
\hline
\end{tabular}

The result of the multilevel analysis is presented below, Adjusted odds ratios (AOR) for 2016 EDHS are shown in Table 4. In multivariable multilevel mixed-effect logistic regression analysis at the individual/household level, the odd of being wasted was more than two times higher among male children, compared to females. Similarly, children from the poorest households had a greater odd of being wasted as compared to children from the richest households. Furthermore, among community-level factors, children living in Oromiya, Harari, and the Addis Abeba regions were associated with having a lower odd of being wasted compared to Tigray. Conversely, children from the Somali region were about 2.7 times more likely to be wasted $(\mathrm{AOR}=2.7,95 \% \mathrm{Cl}=1.7-4.3)$ as compared to children from Tigray.

After fitting the mixed effect model, The odds of being wasted were higher among male children with an AOR of 1.9 [1.3-2.7]. The odds of being wasted were lower in children who are older with an AOR of 0.5[0.2-0.9]. Compared to Tigray region, respondents from Oromia, Benishangul, SNNP, Harari, Addis Ababa, and Dire Dawa regions had lower odds of wasted children's with AOR of 0.3[0.1-0.6], 0.3[0.2-0.7], $0.4[0.2-0.7], 0.3[0.2-0.8], 0.2[0.1-0.8]$, and 0.4[0.2-0.5], respectively (Table 5). 
Table 5

Factors associated with wasting among children in Ethiopia by multilevel logistic regression analysis, EDHS 2019

\begin{tabular}{|c|c|c|c|}
\hline Variables & Model I & Model II & Model III \\
\hline \multicolumn{4}{|l|}{ Sex of child } \\
\hline Male & $1.8(1.3-2.7)^{\star \star \star}$ & - & $1.9(1.3-2.7)^{\star \star \star}$ \\
\hline Female & 1.00 & - & 1.00 \\
\hline \multicolumn{4}{|l|}{ Child's age(months) } \\
\hline $0-5 m$ & 1.00 & - & 1.00 \\
\hline $6-11 \mathrm{~m}$ & $0.7(0.4-1.3)$ & - & $0.6(0.3-1.2)$ \\
\hline $12-23 \mathrm{~m}$ & $0.9(0.6-1.7)$ & - & $1.0(0.5-1.8)$ \\
\hline $24-35 m$ & $0.8(0.5-1.6)$ & - & $0.9(0.5-1.7)$ \\
\hline$>36 \mathrm{~m}$ & $0.5(0.3-0.9)^{\star}$ & - & $0.5(0.2-0.9)^{*}$ \\
\hline \multicolumn{4}{|l|}{ Wealth index } \\
\hline Poorest & 1.00 & & 1.00 \\
\hline Poorer & $0.8(0.5-1.2)$ & - & $1.1(0.6-1.8)$ \\
\hline Middle & $0.6(0.3-1.1)$ & - & $0.8(0.4-1.5)$ \\
\hline Richer & $0.6(0.4-1.1)$ & - & $0.9(0.5-1.7)$ \\
\hline Richest & $0.5(0.2-0.8)^{\star}$ & - & $0.6(0.3-1.4)$ \\
\hline \multicolumn{4}{|c|}{ Source of drinking water } \\
\hline unimproved & $1.4(0.9-2.2)$ & & $1.5(1.0-2.3)^{\star}$ \\
\hline improved & 1.00 & & 1.00 \\
\hline \multicolumn{4}{|l|}{ Region } \\
\hline Tigray & - & 1.00 & 1.00 \\
\hline Afar & - & $1.6(0.9-2.8)$ & $1.1(0.5-2.1)$ \\
\hline Amhara & - & $0.8(0.5-1.4)$ & $0.7(0.4-1.3)$ \\
\hline Oromiya & - & $0.5(0.3-0.8)^{\star}$ & $0.3(0.1-0.6)^{\star \star \star}$ \\
\hline Somali & - & $2.7(1.7-4.3)^{\star \star \star}$ & $1.5(0.7-2.9)$ \\
\hline Benishangul Gumz & - & $0.7(0.3-1.3)$ & $0.3(0.2-0.7)^{\star \star \star}$ \\
\hline SNNP & - & $0.6(0.4-1.3)$ & $0.4(0.2-0.7)^{\star \star \star}$ \\
\hline
\end{tabular}




\begin{tabular}{|llll|}
\hline Variables & Model I & Model II & Model III \\
\hline Gambella & - & $1.5(0.9-2.7)$ & $1.4(0.7-2.9)$ \\
\hline Harari & - & $0.4(0.2-0.8)^{\star}$ & $0.3(0.2-0.8)^{\star}$ \\
\hline Addis Abeba & - & $0.3(0.1-0.7)^{\star}$ & $0.2(0.1-0.8)^{\star}$ \\
\hline Dire Dawa & - & $0.7(0.3-1.2)$ & $0.4(0.2-0.9)^{\star}$ \\
\hline
\end{tabular}

\section{Discussion}

Malnutrition is the most sensitive health indicator that reflects the quality of the health care delivery system and socio-economic progress of a country $[2,9]$. Acute malnutrition or wasting is a health indicator and a critical measure of children's nutritional status [17]. We examined the nutritional status of children aged 6-59 months in Ethiopia through a spatial and multilevel analysis approach based on the 2019 Ethiopian Demographic and Health Survey. This study revealed that $7 \%$ of children in Ethiopia had acute malnutrition in the 2019 national survey. The current magnitude of wasted children is also higher than the national target of $3 \%$ [17]. There are more than a few factors associated with this at both individual and contextual levels. The sex of a child, age of the child, household wealth status, source of water, and region of residence are amongst those predictors; however, family size, vaccination status, place of residence, respondent ANC status, and birth order of the child not deemed significant here.

This study showed that the household wealth index was a significant predictor of children's nutrition status, Children from the poorest household wealth index had higher odds of being wasted than children from the richest households. This finding is supported by previous studies conducted in Ghana[23], Uganda[7], Bangladesh[30], Pakistan[32], and Ethiopia[24, 26, 27]. This might be due to the better household wealth status associated with their ability to improve nutritional choices, high access to health information, attitude change, and address basic nutritional and hygiene behaviours that may prevent nutritional failure. Further, among the main finding of this study, male children had a satisfied association with being wasted more than females. Similar findings have been reported by other studies[7, 30].

The spatial autocorrelation analysis result indicated that acute malnutrition and severe acute malnutrition had a spatial dependency in the 2019 EDHS (Moran's I: 0.21 and 0.11, respectively at p-value 0.01). This result is supported by the findings in Somalia[39],Myanmar[36], and WHO[40] and Global Burden of Disease data[41]. Spatial analysis portrayed that under-five children in the pastoralists region were at higher risk of acute malnutrition compared to other regions; however, acute malnutrition or wasting was also found severe in some pocket areas of SNNP and Gambella. Previous studies were in line with higher level of wasted children in the pastoralists regions [27, 39, 42]. The Afar and Somali regions might be always at risk because of the poor access to the healthcare service and feeding practice depending on their way of life. The finding of both spatial and statistical analyses (Table 5), identified high-risk regions consistently. 
These findings have valuable policy implications for intervention and program design. The hot spot areas of acute and severe malnutrition can be detected at local administrative levels. Generally, these findings are supremely important for the Ministry of Health and Regional Health Bureau to give attention to those hot spot areas to have good progress towards achieving sustainable development goal target for nutrition and under-five mortality and morbidity $[2,16]$.

As a strength, the study used data from a nationally representative population-based study with a high response rate, which results in give high statistical power to infer the characteristics of the study population. Also, the sampling weight was applied to produce reliable estimates. Another important strength of this study is the use of multilevel logistic regression and spatial analysis, which was able to cross validation of results. However, it has the following limitations. The cross-sectional nature of the study prevents causality from being inferred between the independent and dependent variables. Furthermore, this study did not consider spatial covariates that may allow to discover more spatial and temporal structure, which were not investigated as part of the survey.

\section{Conclusion}

Overall the acute malnutrition among under-five children in Ethiopia has remains a public health problem and the distribution of risk was followed the contextual nature of the regions. The hotspot (high risk) areas of both acute and severe malnutrition were detected in the Somali and Afar regions. Moreover, border areas of Gambela and south Omo zone of SNNP regions were at higher acute malnutrition. This spatial distribution might be very fundamental to develop strategies and localized interventions. Similarly, in multilevel analysis both individual and community-level factors were significantly associated with acute malnutrition among children aged 6-59 months. Predictors such as the household living standards and wealth index were consistently related to improved children nutritional status.

Therefore, the fact that the spatial distribution and statistical association were well supported one another showed the distribution is scientifically sound. As a practical recommendation, the authors believe that public health intervention activities designed in a targeted approach to impact high-risk populations as well as geographic regions were vital to narrow acute malnutrition in Ethiopia.

\section{Abbreviations}

AOR-Adjusted Odds Ratio, ANC- Antenatal Care, CSA-Central Statics Agency, Cl-Confidence Interval, CIAFComposite index of anthropometric failure, COR-Crude Odds Ratio, EDHS-Ethiopia Demographic and Health Survey, ICC-Intra Class Correlation Coefficient, LLR-Log-Likelihood Ratio, MOR-Median odds ratio, OR-Odds Ratio, PVC-Proportional Change in Variance, RR-Relative Risk, SNNPR-Southern Nations, Nationalities, and Peoples' Region, WHO- World Health Organization.

\section{Declarations}




\section{Ethics approval and consent to participate}

Since the study was a secondary data analysis of publically available survey data from the DHS program, ethical approval and participant consent were not necessary for this particular study. We requested DHS Program and permission was granted to download and use the data for this study from http://www.dhsprogram.com. There are no names of individuals or household addresses in the data files.

\section{Consent for publication}

Not applicable.

\section{Availability of data and materials}

Data we used for this study are publicly available in the MEASURE DHS program and you can access it from www.measuredhs.com after explaining the objectives of the study. Then after receiving the authorization letter, the data is accessible and freely downloaded.

\section{Competing interests}

The authors declare that they have no competing interests.

\section{Funding}

No funding was obtained for this study.

\section{Authors' Contributions}

Proposal preparation, acquisition of data, analysis, and interpretation of data was done by BT. TD, HS, $\mathrm{SH}, \mathrm{DE}, \mathrm{GG}, \mathrm{MH}, \mathrm{RH}, \mathrm{GGK}$, and GA guided the study design data extraction and analysis. BT drafted the manuscript and all authors have a substantial contribution in revising and finalizing the manuscript. All authors read and approved the final manuscript.

\section{Acknowledgments}

We would like to thank the DHS program, for providing the dataset used in this study.

\section{Authors' information}


${ }^{1}$ School of public health, Dilla University, Dilla, Ethiopia. ${ }^{2}$ Department of Pediatrics and Child Health, College of Medicine and Health Sciences, Wollo University, Dessie, Ethiopia. ${ }^{3}$ Department of Health informatics, College of Health Sciences, Mettu University, Mettu, Ethiopia. ${ }^{4}$ Department of Health Informatics, Arbaminch University, Arbaminch, Ethiopia. ${ }^{5}$ School of public health, Dilla University, Dilla, Ethiopia. ${ }^{6}$ School of public health, Dilla University, Dilla, Ethiopia. ${ }^{7}$ Department of Health informatics, College of Health Sciences, Mettu University, Mettu, Ethiopia. ${ }^{8}$ School of public health, Dilla University, Dilla, Ethiopia. ${ }^{9}$ School of public health, Dilla University, Dilla, Ethiopia. ${ }^{10}$ School of public health, Dilla University, Dilla, Ethiopia.

\section{References}

1. National Dairy Research Institute, Annual Technical Report. 2011, J Chem Inf Model. p. 1-116.

2. World Health Organization. World health statistics 2016: monitoring health for the SDGs sustainable development goals. 2016.

3. Sileshi A. Prevalence's of Wasting and its Associated Factors of Children among Months Age in Guto Gida District, Oromia Regional State, Ethiopia. Journal of Food Processing and Technology 2013. 05(01).

4. Motbainor A, Taye A. Wasting in under five children is significantly varied between rice producing and non-producing households of Libokemkem district, Amhara region, Ethiopia. BMC Pediatrics. 2019;19(1):300.

5. Poulia KA, et al. The two most popular malnutrition screening tools in the light of the new ESPEN consensus definition of the diagnostic criteria for malnutrition. Clin Nutr. 2017;36(4):1130-5.

6. Berra WG. Household Food Insecurity Predicts Childhood Undernutrition: A Cross-Sectional Study in West Oromia (Ethiopia). Journal of Environmental Public Health. 2020;2020:5871980.

7. Odei Obeng-Amoako GA, et al. Factors associated with concurrent wasting and stunting among children 6-59 months in Karamoja. Uganda Maternal Child Nutrition. 2021;17(1):e13074.

8. Singer PA, Ansett S, Sagoe-Moses I. What could infant and young child nutrition learn from sweatshops? BMC Public Health. 2011;11(1):276.

9. World Health Organization and World Bank. levels and trends in child malnutrition: key findings of the 2020 edition, in Nutrition and Food Saftey. Editor: W.H. Organization; 2020.

10. Akombi BJ, et al., Stunting, Wasting and Underweight in Sub-Saharan Africa: A Systematic Review. Int J Environ Res Public Health, 2017. 14(8).

11. Restrepo-Méndez MC, et al. Time trends in socio-economic inequalities in stunting prevalence: analyses of repeated national surveys. Public Health Nutr. 2015;18(12):2097-104.

12. Trehan I, Manary MJ. Management of severe acute malnutrition in low-income and middle-income countries. Arch Dis Child. 2015;100(3):283-7.

13. World Health Organization. World health statistics. Geneva; 2021. 
14. UNICEF and World Health Organization. Levels and trends in child malnutrition: key fndings of the 2018 edition of child malnutrition estimates. Geneva; 2018.

15. Seife Ayele EAZ, Nisbett N. Multi-Sectoral Nutrition Policy and Programme Design, Coordination and Implementation in Ethiopia. IDS; 2020.

16. Moss $C$, et al. Sustainable Undernutrition Reduction in Ethiopia (SURE) evaluation study: a protocol to evaluate impact, process and context of a large-scale integrated health and agriculture programme to improve complementary feeding in Ethiopia. BMJ Open. 2018;8(7):e022028.

17. Walls $\mathrm{H}$, et al., The Role of Evidence in Nutrition Policymaking in Ethiopia: Institutional Structures and Issue Framing, in Evidence Use in Health Policy Making: An International Public Policy Perspective, J. Parkhurst, S. Ettelt, and B. Hawkins, Editors. 2018, Springer International Publishing: Cham. p. 51-73.

18. Central Statistical Agency (CSA). Ethiopia. Ethiopia Demographic and Health Survey (EDHS) 2011 Key Indicators Report. 2011: Addis Ababa, Ethiopia and Calverton, Maryland.

19. Central Statistical Agency (CSA). Ethiopia. Ethiopian Demographic and Health survey 2005. 2005: Addis Ababa, Ethiopia and calverton, maryland, USA.

20. Central Statistical Agency (CSA). Ethiopia, Ethiopia Demographic and Health Survey (EDHS) 2016 Key Indicators Report. Maryland: Addis Ababa, Ethiopia and Calverton; 2016.

21. Central Statistical Agency (CSA). Ethiopia. Ethiopian Mini Demographic and Health Survey, Preliminary Report. 2019: Addis Ababa, Ethiopia and Calverton, Maryland: CSA and ORC Macro.

22. Amare D, et al., Prevalence of Undernutrition and Its Associated Factors among Children below Five Years of Age in Bure Town, West Gojjam Zone, Amhara National Regional State, Northwest Ethiopia. Advances in Public Health, 2016. 2016: p. 1-8.

23. Ali $Z$, et al. The effect of maternal and child factors on stunting, wasting and underweight among preschool children in Northern Ghana. BMC Nutrition. 2017;3(1):31.

24. Ma'alin A, et al. Magnitude and factors associated with malnutrition in children 6-59 months of age in Shinille Woreda, Ethiopian Somali regional state: a cross-sectional study. BMC Nutrition. 2016;2(1):44.

25. Asfaw $M$, et al. Prevalence of undernutrition and associated factors among children aged between six to fifty nine months in Bule Hora district, South Ethiopia. BMC Public Health. 2015;15(1):41.

26. Bokore A, Wolde T, Melka A. Determinants of acute malnutrition among children aged 6-59 months in Public Hospitals, Oromia region, West Ethiopia: a case-control study. BMC Nutrition, 2015. 1.

27. Kahssay M, et al. Determinants of stunting among children aged 6 to 59 months in pastoral community, Afar region, North East Ethiopia: unmatched case control study. BMC Nutrition. 2020;6(1):9.

28. Abitew DB, et al. Predictors of relapse of acute malnutrition following exit from community-based management program in Amhara region, Northwest Ethiopia: An unmatched case-control study. PLOS ONE. 2020;15(4):e0231524. 
29. Abitew D, et al. Rural children remain more at risk of acute malnutrition following exit from community based management of acute malnutrition program in South Gondar Zone, Amhara Region, Ethiopia: a comparative cross-sectional study. PeerJ. 2020;8:e8419.

30. Hoq $M$, et al. Risk factors of acute malnutrition among children aged 6-59 months enrolled in a community-based programme in Kurigram, Bangladesh: a mixed-method matched case-control study. Journal of Health Population Nutrition. 2019;38(1):36.

31. Teferi H, Teshome T. Magnitude and Associated Factors of Undernutrition Among Children Aged 659 Months in Ethiopian Orphanage Centres. Pediatric Health Med Ther. 2021;12:141-50.

32. Khan S, Zaheer S, Safdar NF. Determinants of stunting, underweight and wasting among children $<5$ years of age: evidence from 2012-2013 Pakistan demographic and health survey. BMC Public Health. 2019;19(1):358.

33. Batiro B, et al. Determinants of stunting among children aged 6-59 months at Kindo Didaye woreda, Wolaita Zone, Southern Ethiopia: Unmatched case control study. PLOS ONE. 2017;12(12):e0189106.

34. Demilew YM, Alem AT. Food security is not the only solution to prevent under-nutrition among 6-59 months old children in Western Amhara region, Ethiopia. BMC Pediatrics. 2019;19(1):7.

35. Muthén B, and TA, Beyond multilevel regression modeling: Multilevel analysis in a general latent variable framework, in Handbook of advanced multilevel analysis. 2011. p. 15-40.

36. Blankenship $\mathrm{JL}$, et al. Childhood stunting and wasting in Myanmar: Key drivers and implications for policies and programmes. Maternal Child Nutrition. 2020;16(S2):e12710.

37. M, K., A spatial scan statistic, in Common Statistics Theory Methodology 1997. p. 1481-1496.

38. Zimmerman DL, Z., comparison of spatial semivariogram estimators and corresponding ordinary kriging predictors. 1991, Technometrics. p. 77-91.

39. Kinyoki DK, et al. Space-time mapping of wasting among children under the age of five years in Somalia from 2007 to 2010. Spatial Spatio-temporal Epidemiology. 2016;16:77-87.

40. Almasi A, et al. Study of the Spatial Pattern of Malnutrition (Stunting, Wasting and Overweight) in Countries in the World Using Geographic Information System. International Journal of Pediatrics. 2019;7(10):10269-81.

41. Mapping local patterns of childhood overweight and wasting in low-and middle-income countries between 2000 and 2017. Nat Med, 2020. 26(5): p. 750-759.

42. Gebreyesus $\mathrm{SH}$, et al. Local spatial clustering of stunting and wasting among children under the age of 5 years: implications for intervention strategies. Public Health Nutrition. 2016;19(8):1417-27.

\section{Figures}


Regional distribution of wasted and severely wasted children

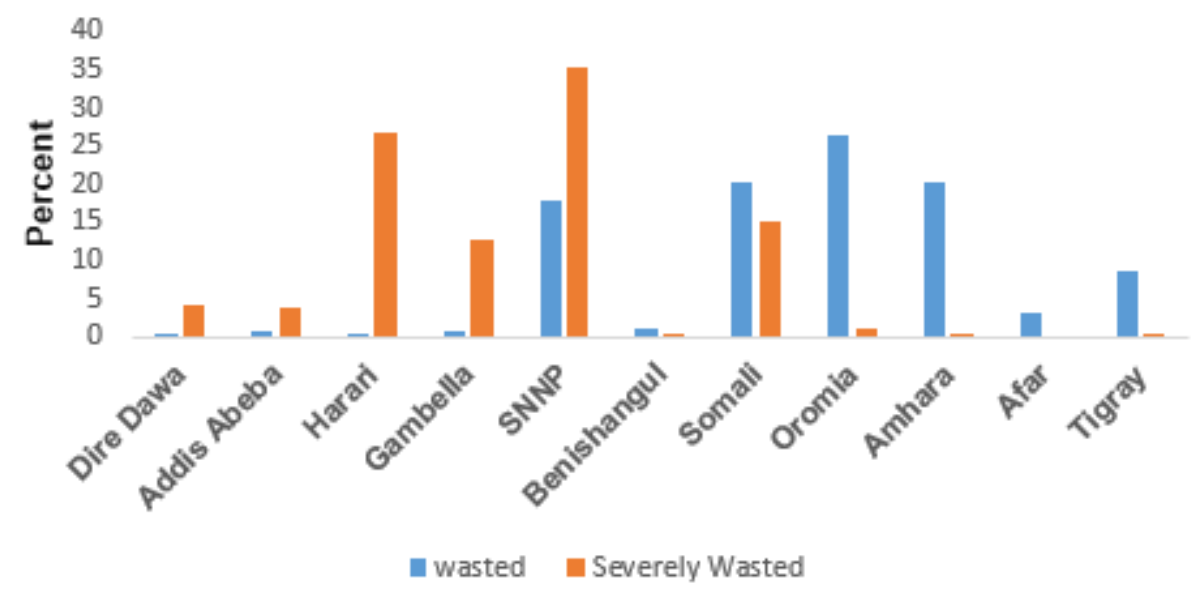

Figure 1

Acute and severe malnutrition among children aged 6-59 months in Ethiopia, 2019 EDHS

Moran's Index: 0.206933

z-score: 4.586520

p-value: 0.000005

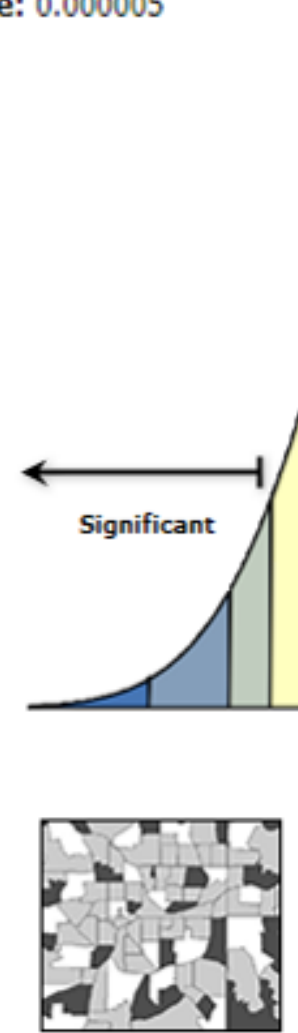

Dispersed

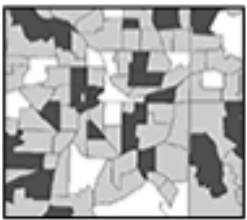

Random
Critical Value

(z-score)

$0.01 \square-2.58$
$0.05 \square-2.58--1.96$

$0.10 \square-1.96--1.65$

$\cdots \quad \square \quad-1.65-1.65$

$0.10 \square \quad 1.65-1.96$

$0.05 \square 1.96-2.58$

$0.01 \square>2.58$

Figure 2 
The global spatial autocorrelation of wasted children in Ethiopia, 2019 EDHS

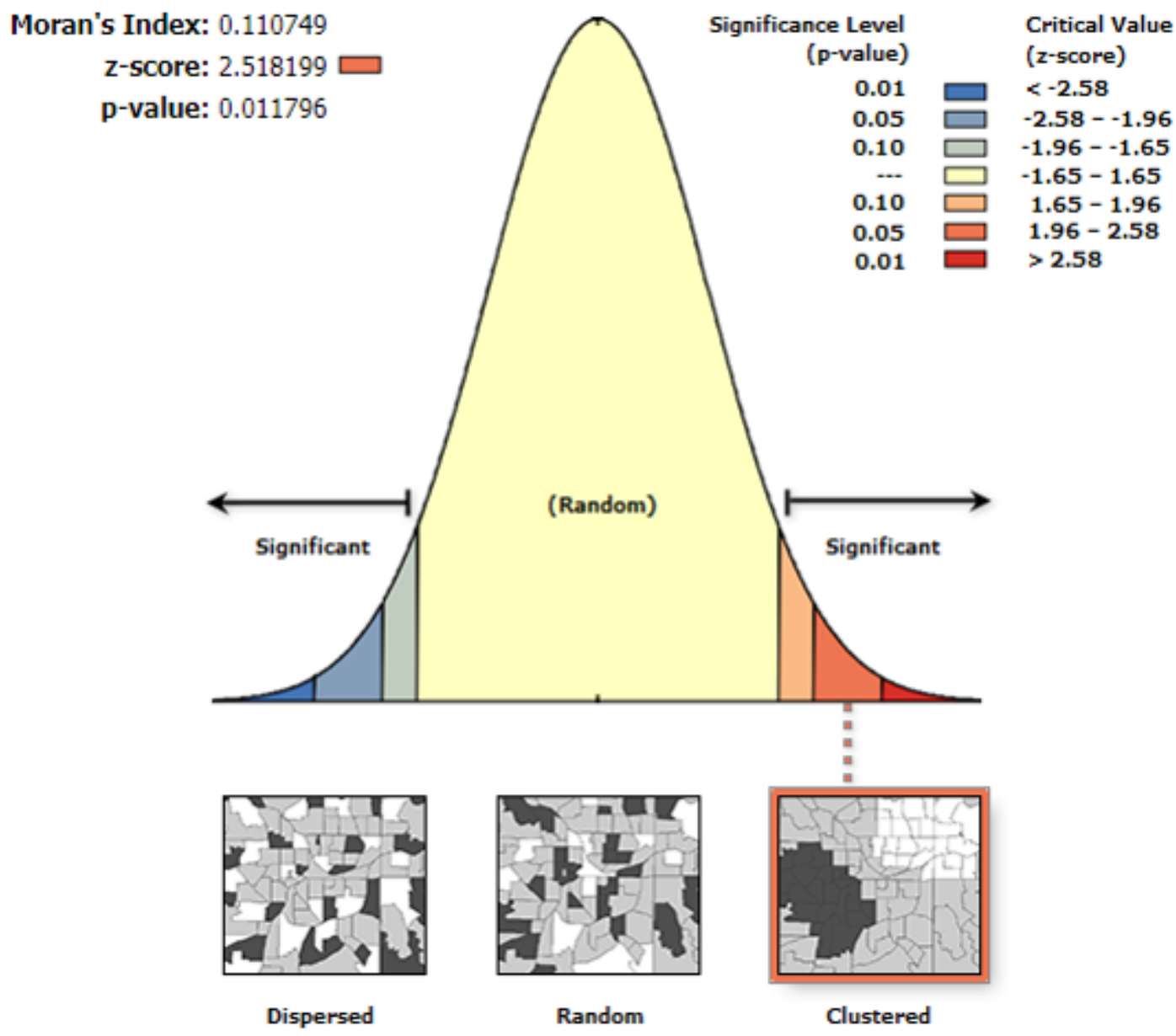

\section{Figure 3}

The global spatial autocorrelation of severely wasted children in Ethiopia, 2019 EDHS 


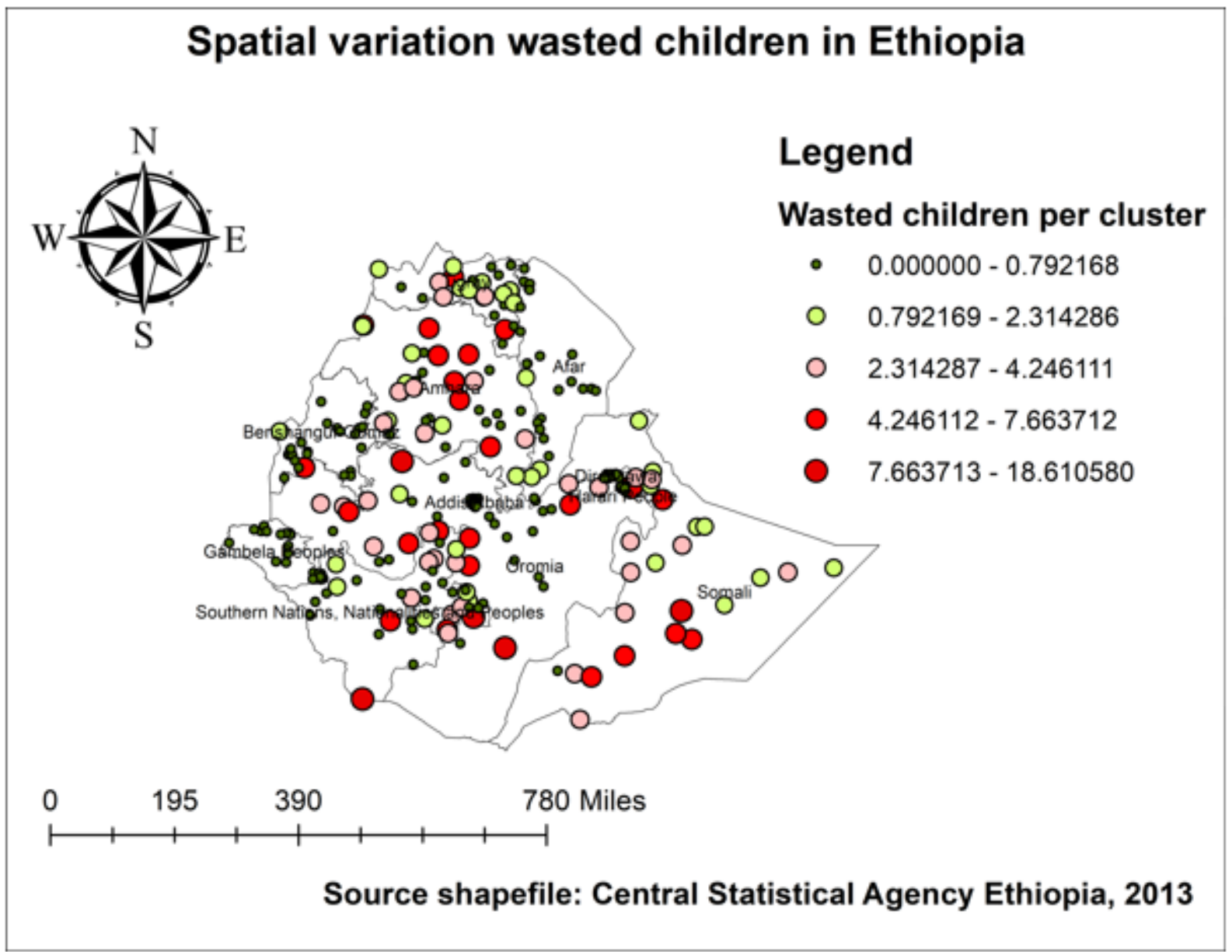

Figure 4

Spatial distribution of wasting among under-five children in Ethiopia, 2019 EDHS 


\section{Spatial variation of severely wasted children in Ethiopia}

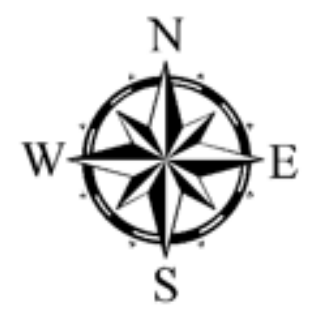

\section{Legend}

Severely wasted children per cluster

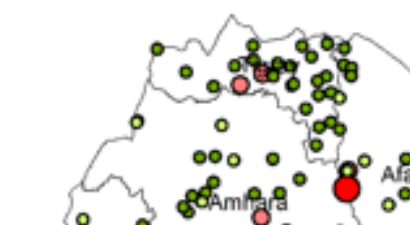

$\circ 0$

$\circ 1$

○ 2

- $3-4$

( $5-6$
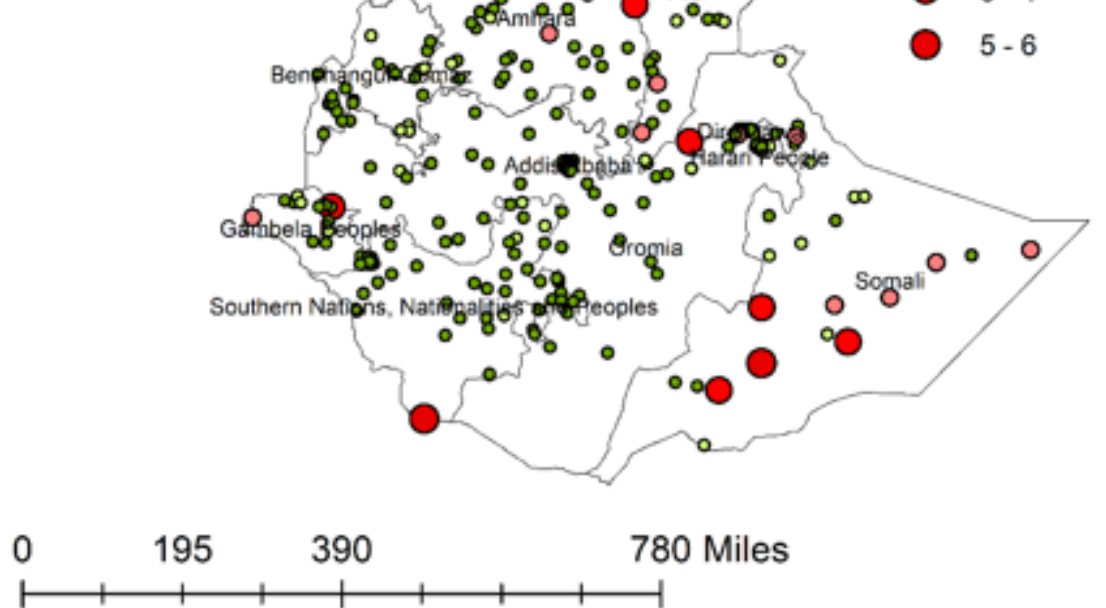

Source shapefile: Central Statistical Agency Ethiopia, 2013

Figure 5

Spatial distribution of severely wasted under-five children in Ethiopia, 2019 EDHS 


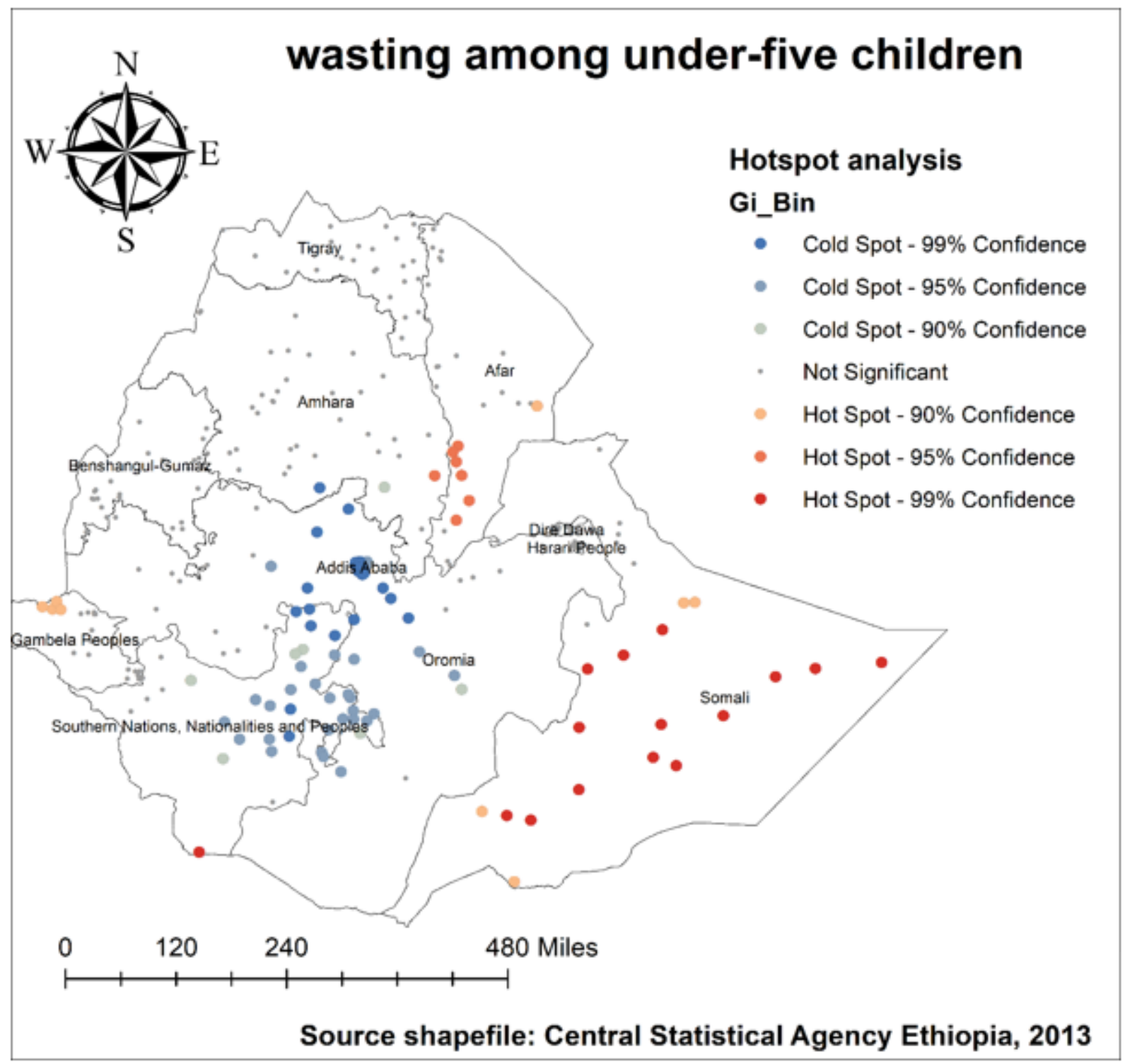

Figure 6

Hotspot analysis of wasting among under-five children in Ethiopia, 2019 EDHS 


\section{Severely wasted under-five children in Ethiopia}

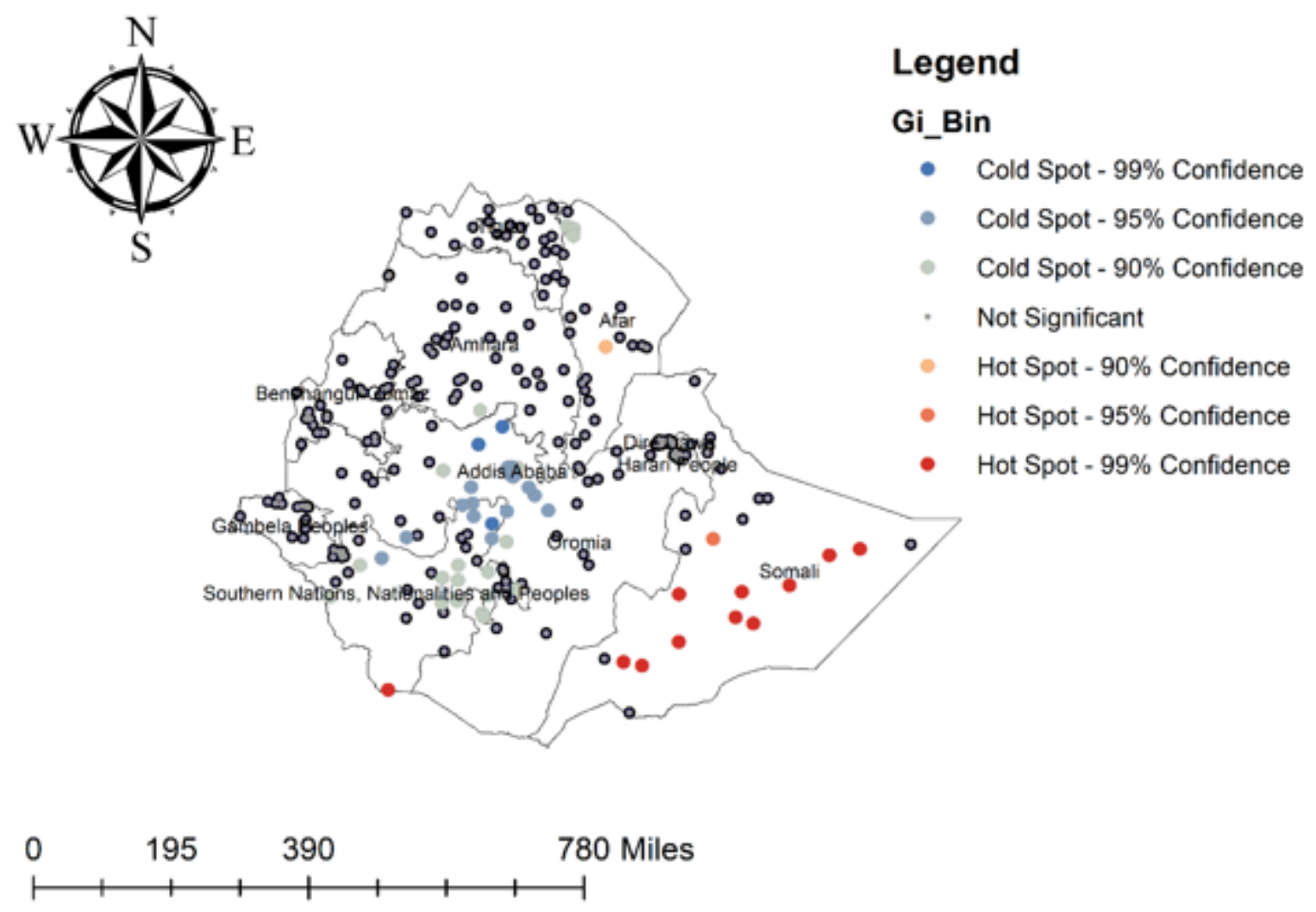

Source shapefile: Central Statistical Agency Ethiopia, 2013

Figure 7

Hotspot analysis of severely wasted under-five children in Ethiopia, 2019 EDHS 


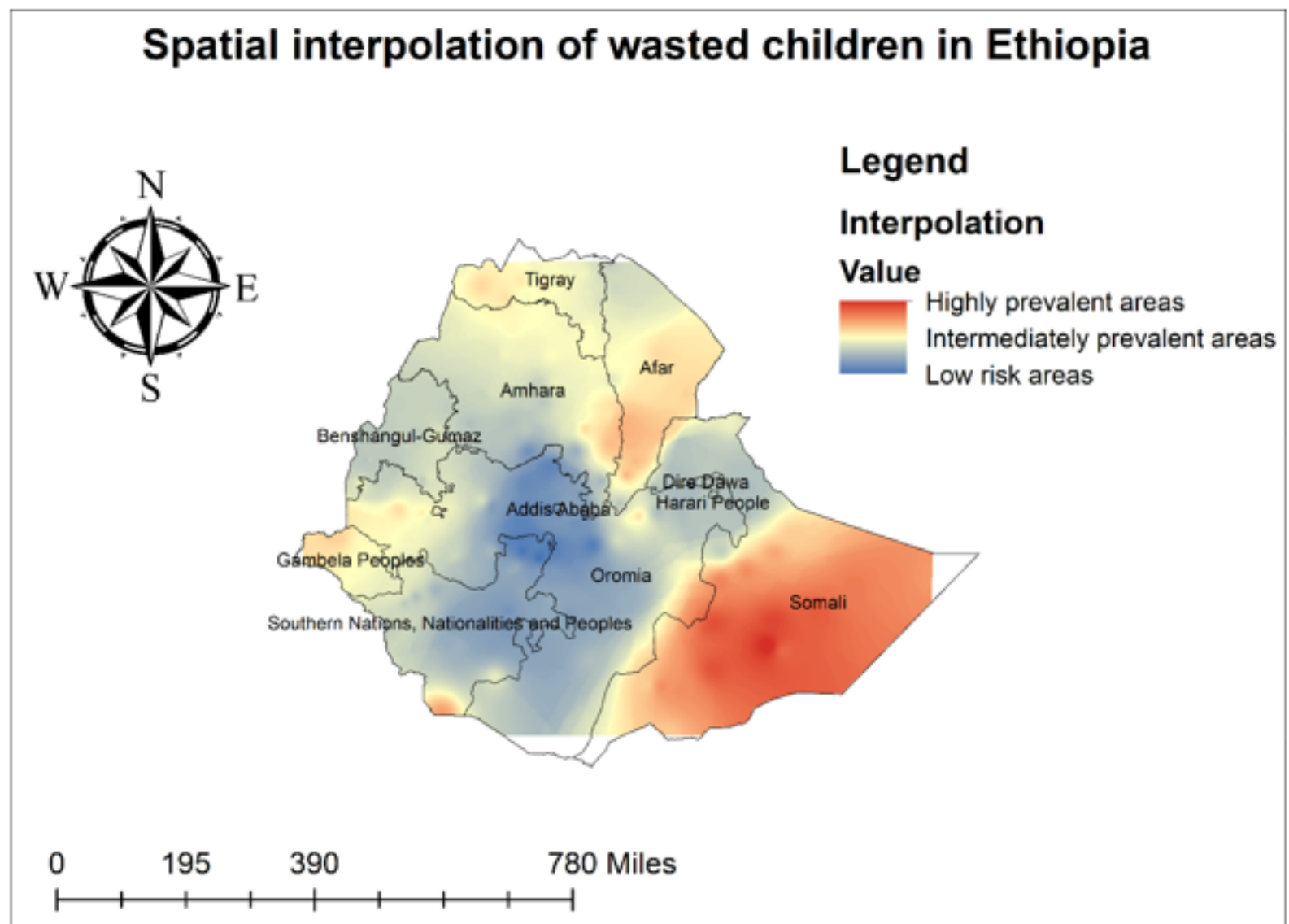

Source shapefile: Central Statistical Agency Ethiopia, 2013

Figure 8

Spatial Interpolation of wasting among under-five children in Ethiopia, EDHS 2019 


\section{Spatial interpolation of severely wasted children in Ethiopia}
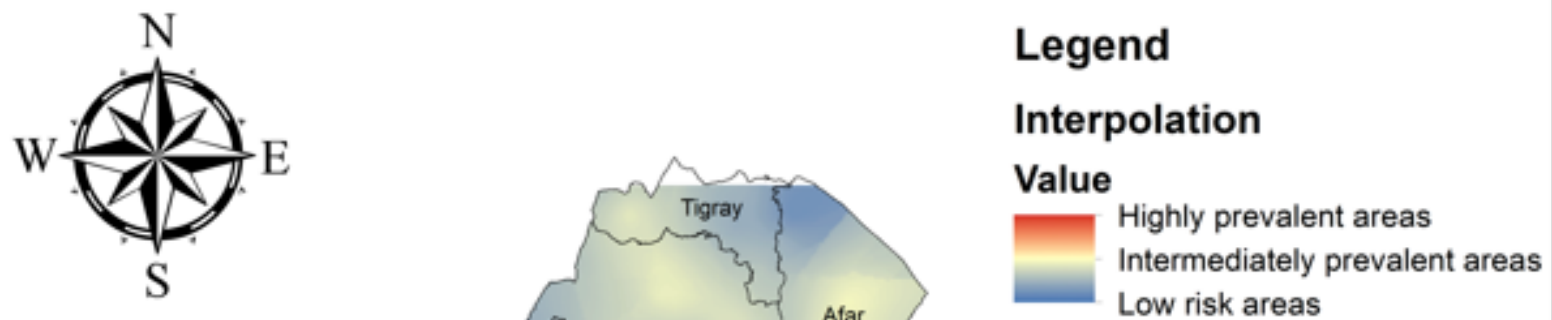

$0 \quad 195 \quad 390 \quad 780$ Miles

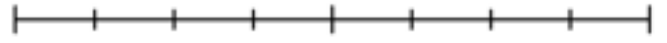

Source shapefile: Central Statistical Agency Ethiopia, 2013

Figure 9

Spatial Interpolation of severely wasted children in Ethiopia, EDHS 2019 


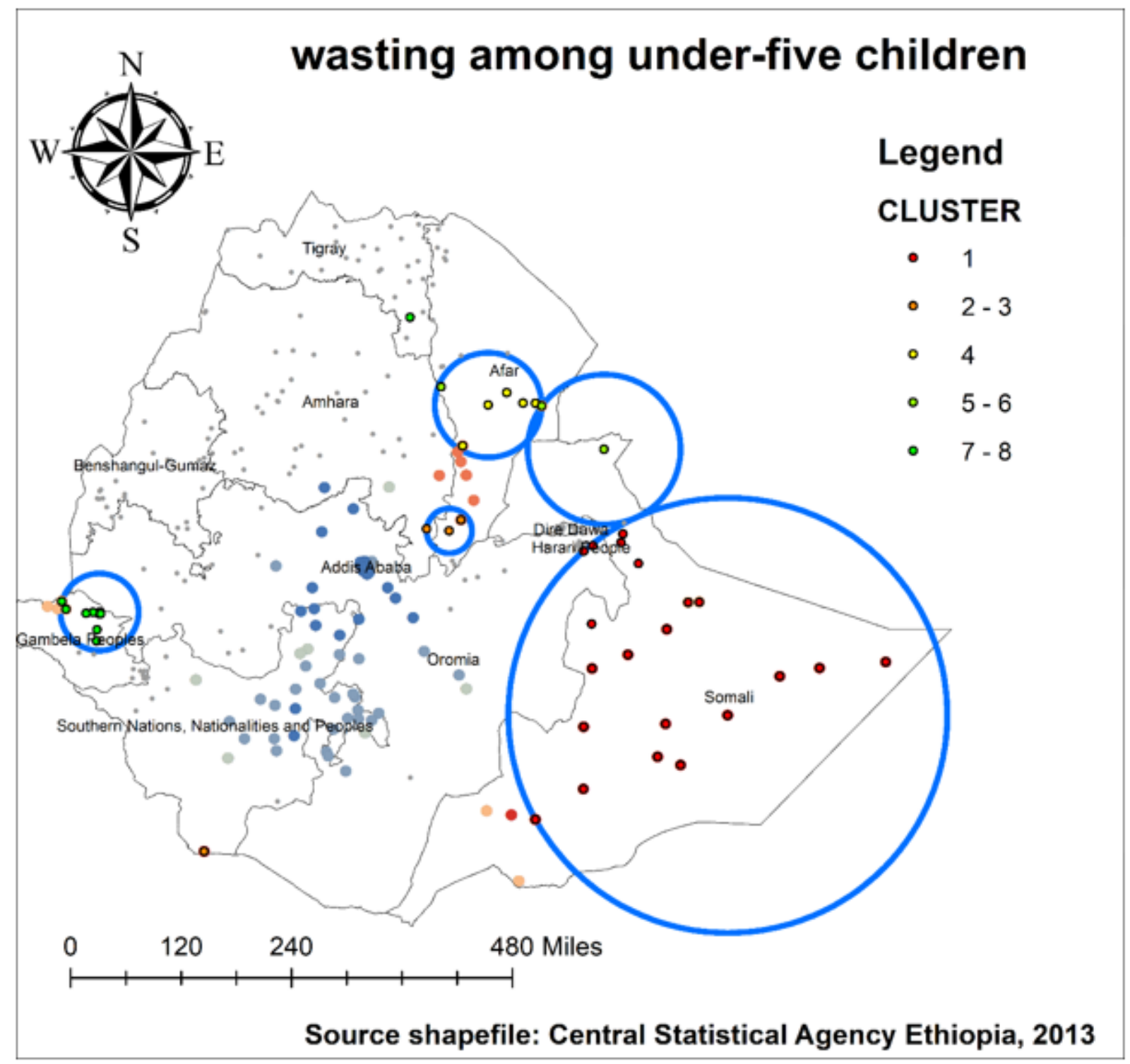

Figure 10

SaTScan scan analysis of wasting among under-five children in Ethiopia, 2019 EDHS 


\section{SatScan analysis of severely wasted children in Ethiopia}
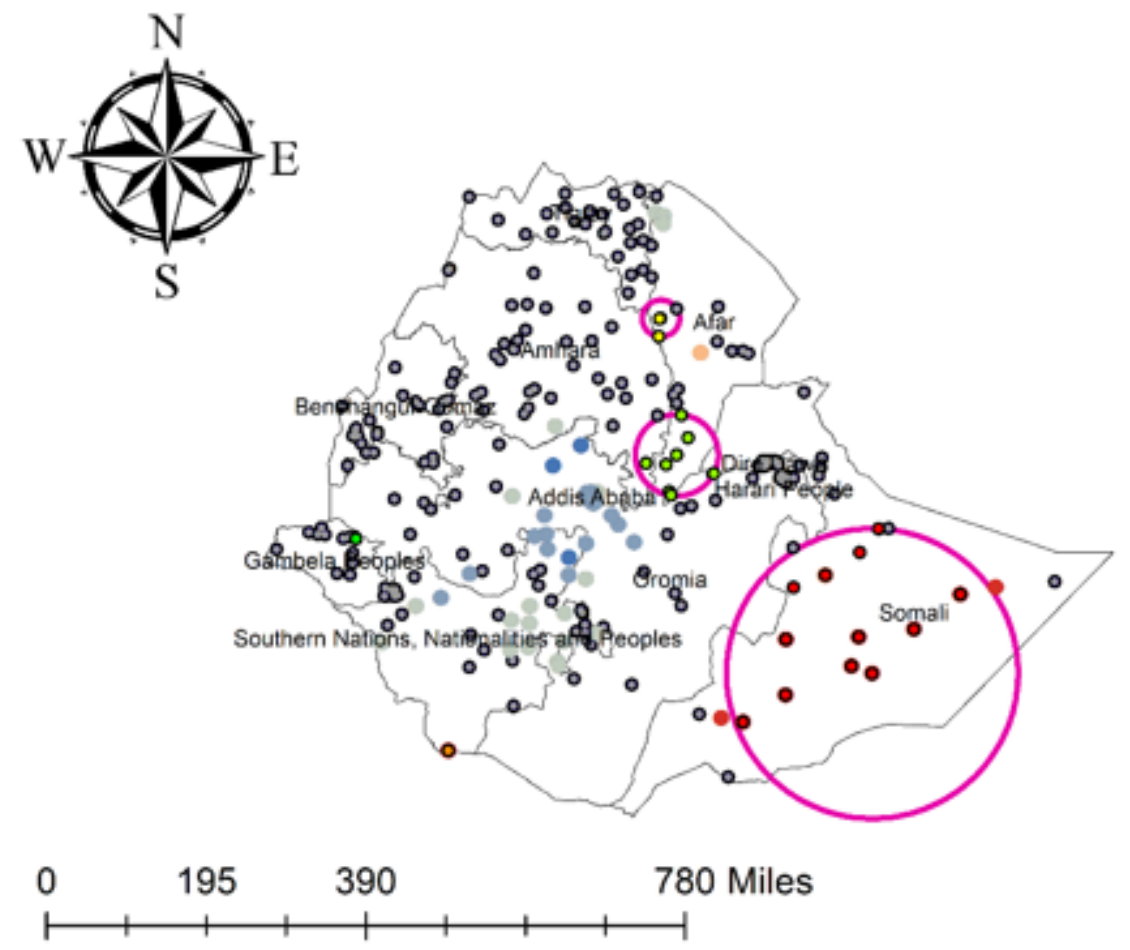

Legend

CLUSTER

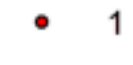

- 2

- 3

- 4

- 5

Source shapefile: Central Statistical Agency Ethiopia, 2013

Figure 11

SaTScan scan analysis of severely wasted children in Ethiopia, 2019 EDHS 